\title{
Business Excellence Models: \\ Limitations, Reflections and Further Development
}

\author{
Jens J. Dahlgaard \\ Linköping University, Sweden. \\ jens.jorn.dahlgaard@liu.se \\ Chi-Kuang Chen \\ Yuan Ze University, Taiwan. \\ ieckchen@saturn.yzu.edu.tw \\ Jiun-Yi Jang \\ Yuan Ze University, Taiwan \\ Leonardo A. Banegas \\ Yuan Ze University, Taiwan \\ Su Mi Dahlgaard-Park \\ Department of Service Management \\ Lund University, Sweden. \\ sumi.park@msm.lu.se
}

\begin{abstract}
The use of Business Excellence Models (BEM) has become popular in the last two decades and several companies have learned from such models and learned how to use them. More companies, we guess, have experienced problems when using such models because of various weaknesses such as too sophisticated assessment criteria, excessive paperwork, cumbersome procedures, and a lack of focus which have limited its use in practice. To respond to some of those problems a new overall Business Excellence Framework (BEF) has been developed which invites for adaption instead of adoption of existing BEMs. The suggested overall BEF helps to integrate BEM with management tools/techniques and the organizational culture/characteristics for guiding an organization towards BE. A document-based empirical case of a world-class company, Boeing Aerospace Support, is being investigated to illustrate how the overall BEF may work in practice as a complement to an existing BEM when companies adapt such models to their specific contexts.
\end{abstract}

Keywords: Business Excellence Models; Total Quality Management; 4P Excellence Model, MBNQA; EFQM Excellence Model; Self-assessment; Change Management 


\section{Introduction}

In order to respond to the highly competitive external environment enterprises continuously search for new effective approaches to enhancing their management capabilities such as Total Quality Management (TQM), Business Excellence Models (BEM), Business Process Reengineering (BPR), Enterprise Resource Planning (ERP), Organizational Change Management (OCM) etc. Among these various approaches TQM and Business Excellence Models have been among the most popular ones in the past two decades.

The existing BEM have in most cases been developed or been supported by national bodies as a basis for award programs and for the widespread adaption of the principles and methods of TQM and Business Excellence. Today, more than 80 national and state/regional awards base their frameworks upon the Malcolm Baldrige National Quality Award (MBNQA) criteria or the European Foundation for Quality Management (EFQM)/ European Excellence Award criteria (Mann, 2011), and around 30,000 European organizations were using the European Excellence Model in 2006 (Heras-Saizarbitoria, 2012).

Some research indicates that organizations implementing TQM/ BEM will obtain significant benefits including both increased financial profit (Hendricks \& Singhal, 1996; Hausner, 1999; Hendricks \& Singhal, 2000; Hansson \& Eriksson, 2002; Jacob et al., 2004; Boulter et al., 2013) and non-financial outcomes (GAO, 1991; Powell, 1995; Curkovic et al., 2000; Hoisington \& Huang, 2000; Douglas \& Judge, 2001.

The most recent research on the financial impacts of implementing TQM and BEM (Boulter et al., 2013) compared 120 national, regional and European award winning companies from the period 1990 to 2006 with careful selected comparison companies from the same industry and country as the award winning company. The analyzed companies were all publicly traded. Like the study by Hendrics \& Singhal, which compared 600 award winning companies in North America with selected comparison companies from the same industry, no significant differences in financial results could be found in the implementation period (5 years before the award). During the post implementation period ( 5 years after the award was given) differences between the two groups of companies became bigger and bigger on several financial results. Compared to the comparison companies, award winning companies experienced 1 year after the award a further $8 \%$ mean increase in sales revenues, which increased to $17 \% 3$ years after the award, and $77 \% 5$ years after the award. The award winning companies showed further 5 years after the award a higher mean increase of $18 \%$ in operating income, $40 \%$ in total assets, and a $4.4 \%$ further reduction in cost over sales.

Comparing the award winning companies' share values with the S\&P European 
index showed that during the post implementation period the increase in the award winning companies' share values outperformed this index with an increasing margin, and for the period 1 year before the award to 5 years after the award the average share value of the award winning companies had increased 102\% more than the S\&P index.

The conclusions from this most recent research project on the financial impacts of implementing TQM and BEM were among others:

- Investing in Excellence as a core of business strategy pays!

- Objective evidence for this now exists in both North America and Europe.

- Excellence strategies contribute to business performance through increased sales and also through reduced cost and process efficiency.

However, not all findings in the literature are positive. Some research findings indicate that the use of BEM does not guarantee success (Powell, 1995; Jennings \& Beaver, 1997; Fisher et al., 2001; Stephens et al., 2005), and companies complain that they encounter difficulties in using such models.

Why are the research findings inconsistent? Why do companies encounter difficulties when using BEM? Answering these questions is challenging. It is an intrinsically complicated issue which involves many factors such as the degree of motivation \& commitment, the degree of people involvement, size of the organization, the industrial sector, the organizational structure \& system infrastructure, organizational culture, and companies’ degree of quality maturity, etc.

The literature on implementation of TQM and BEM programs has identified a wide range of barriers which also may explain the variation/ inconsistencies. These barriers are among others: Lack of top management commitment, limited resources, fear of change, work overload, lack of comprehensive quality improvement education, lack of staff involvement (Corbett \& Angell, 2011). In this relation it has also been pointed out that one of the invisible barriers is how BEMs are perceived and understood by the users because people's perceptions and understanding guide the behavior in the context of using such models (Dahlgaard-Park, 2008).

To help in understanding and coping with the reported problems of using BEM this article we will first take a closer look at some of the potential weaknesses/ limitations in section 2 and try to discuss, analyze and respond to some of the most common potential weaknesses/limitations.

After that a simplified BEM (the " $4 P$ " Excellence Model) will be presented in section 3 which has been developed and re-developed during the last 12 years to address some of the application problems with existing BEMs. The " $4 P$ " Excellence Model functions in this article both as a "stepping stone" for an overall BEF (Business Excellence Framework) presented and discussed in section 4, and also as a well tested example of using a simplified BEM where model criteria and potential areas to 
address (key performance indicators) have to be adapted to company contexts.

The suggested overall BEF in section 4 has been developed in order to show light on the critical factors which should be part of or integrated with any BEM. The suggested overall BEF complements existing BEMs by pointing to the importance of integrating management tools/techniques and organizational culture elements with existing BEMs.

A case study will be included in section 5 to show how the suggested overall BEF may work in a specific context as a complement to an existing BEM (the MBNQA framework) illustrating how a company has adapted a BEM to its specific context. The case is about Boeing Aerospace Support which was a recipient of the 2003 MBNQA winner in services. The article will end up in section 6 with a short conclusion and implication section.

\section{Limitations of Business Excellent Models}

One research category regarding potential limitations of existing BEMs is related to the poor performance of past MBNQA winners such as Cadillac, Federal Express, Wallace and Motorola. Such examples have led some management experts and professionals to question the value of such awards.

The responding argument is very simple and hence do not need much discussions. Even if the use of BEMs can produce both financial and non-financial benefits to an organization it is evident that a National Quality Award can not be a guarantee for long-term success (ex. Wisner \& Eakins, 1994; Powell, 1995; Melnyk \& Denzler, 1996; Fisher et al., 2001; Evans, 2012).

Another research category points to the potential weaknesses related to the operations of self-assessment in relation to award applications (Miller, 1993; McTeer \& Dale, 1994; Wilkes \& Dale, 1998; Lee et al., 2006). Weaknesses include too sophisticated assessment criteria, excessive paperwork, cumbersome procedures, lack of infrastructure, excessive bureaucracy, time consuming, and a lack of focus (Main, 1991).

Three responding arguments will be discussed in the following in response to some of the most common reported limitations/ weaknesses related to the operations of self-assessment. Those 3 arguments or discussion points are based on our literature review combined with two of the authors' experiences with assessing quality award applications as external assessors and jury members of the Danish, the Swedish and the Taiwanese Quality Awards.

The first argument/discussion point is, what award organizations claim, that the existing BEMs are essentially non-prescriptive frameworks designed mainly for assessment of award applications and hence they do not provide specific guidelines 
for management control purposes including the application of management tools and techniques. However, a counter argument is that companies need help when using the same models for management control purposes. Application problems for such purposes are related to the following two questions:

1. How to do self-assessment for other applications?

2. How to decide on the weights (the importance) of the various BEM criteria?

Companies have to find their own ways to do simple and regular self-assessments which are not so resource demanding as award application assessments. They also have to find new ways to involve their employees in the regular assessments. One such way is a questionnaire approach where employees are invited to assess selected key performance indicators (= potential areas to address) related to each criterion as well as their perceived importance (Dahlgaard et al., 2011).

The second argument/discussion point is that the existing BEM are not sufficiently persuasive to yield "Total Employee Involvement" which we assume to be the most critical success factor in the pursuit of BE. The structure and language of existing BEM invite for "expert involvement" in stead, and hence the tradition has become that their use has become dominated almost exclusively by experts and consultants. Research in this area however shows that cooperation and teamwork are necessary ingredients for successful BEM initiatives (Chapman, 2000; Jackson, 2001; Dahlgaard \& Dahlgaard-Park, 2004; Dahlgaard et al., 2011; Dahlgaard-Park, 2012). It is generally the case that the complexity of most processes places them beyond the control of any individual and thus the only efficient way to tackle process improvements is through effective teamwork which relies on the premise that people are willing and able to support any effort in which they are expected and trusted to participate (Oakland, 1999; Dahlgaard-Park, 2012). The reported operational weaknesses however may hinder employees from sufficient involvement in self-assessment and continuous improvements.

The third argument/discussion point is that despite having a holistic perspective at its conceptual level the existing models lack guidance for integration at the operational/process level. This argument is surprising when studying for example the European Excellence Model (2010) where EFQM claims that:

"The EFQM Excellence Model is a practical, non-prescriptive framework that enables organizations to: Integrate existing and planned initiatives, removing duplication and identifying gaps.”

However one possible root cause for lacking integration may be the identified inconsistencies between intentions and practices within the EFQM Model (Dahlgaard-Park, 2008): 
"The inconsistency is observed between leadership intention and the practices (processes), in particular. The culture aspect in terms of value, vision and mission building was explicitly focused under Leadership, while this focus was more or less ignored in Strategy, Partnership \& Resources as well as in the Process criterion. These inconsistencies seem to be a major defect of the model and may have been the reason for many companies' problems with implementing the model as an overall framework for strategic planning and improvement of the business. Also in relation to an award approach these inconsistencies seem to be a major problem both for companies applying for the European Quality Award and for the examiners."

Even if the latest version of the EFQM Excellence Model (2010) has been improved by focusing more on achieving "a full integration of the Fundamental Concepts of Excellence and the framework of the model" we still find that the framework has the above inconsistency related to the values and culture aspects. Here it is especially critical that Strategy only refers to core competencies and not to core values and core value deployment. It is not enough for assuring sufficient integration what we can read under the Leadership criterion 1d, that "Leaders reinforce a culture of excellence with the organization's people". It is a long process from leadership intentions to leadership practices in the many processes which in some way define a company.

Another possible root cause for lacking integration is related to the many criteria and sub-criteria of existing BEM. The EFQM Excellence Model, for example, consists of 9 criteria and 32 sub-criteria, which break down organizational management into a too excessive fragmentation that may result in self-assessments lacking integration and focus.

Excessive fragmentation may be symbolized with the old saying that focusing on the many trees in a forest may hinder observers to see the whole, meaning it may hinder assessors and especially the management team to see and understand the whole management system and to understand the most important relationships between its components specified in the BEM as criteria and sub-criteria.

In the following section we will present and discuss a simplified excellence model which was developed to address some of the potential limitations of existing BEM. 


\section{The "4P" Excellence Model}

An important motivation behind the "4P" excellence model (Dahlgaard-Park \& Dahlgaard, 2008, 2010; Dahlgaard et al., 2011) has been to create a model that provides an integrated approach between various and often conflicting aspects such as soft (intangible) and hard (tangible) aspects, subjective and objective aspects, rational and irrational aspects, individual/personal and collective/organizational aspects, as there is no BEM model which embraces those different aspects of organizational realities. The '4P' model provides a recommended structure or sustainable strategy for achieving innovation excellence (Dahlgaard and Dahlgaard-Park (2011). According to the model building quality or excellence into the following ' $4 \mathrm{P}$ ' is a precondition for 'Organizational Excellence’ (OE): 1. People, 2. Partnership/ Teams, 3. Processes of work, 4. Products /Services. The " $4 \mathrm{P}$ " excellence model is shown below in two different versions (Figures 1a and 1b) which we will refer to in the following. The two different versions of the same model give the same message with different metaphors.

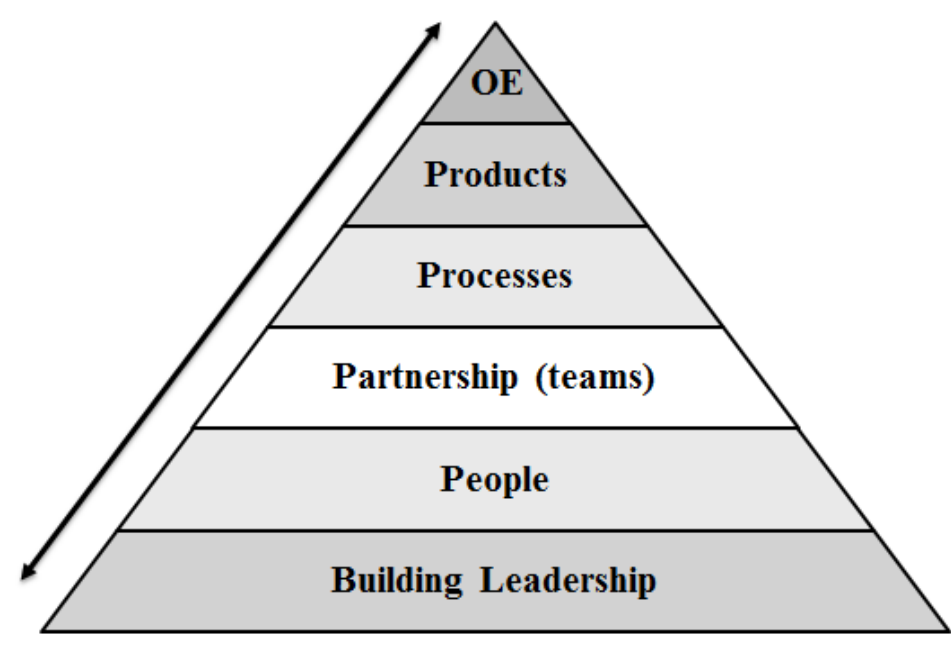

Figure 1a. Building OE through the " $4 \mathrm{P}$ "

Figure 1a uses a pyramid as the metaphor and the resulting model is close to Liker's pyramid model for understanding Toyota's Production System (Liker, 2004; Dahlgaard \& Dahlgaard-Park, 2006).

Figure $1 \mathrm{~b}$ shows that the "4P" excellence model is an 'enabler-result model' with five criterions, where the first four criterions are the so-called enablers or the critical success factors (CTF) for the results - products and services (Dahlgaard et al., 2011). The four enablers comprise a system of four interrelated components, where the first three enablers (components) may be called the management system, and the fourth enabler - the process component - develops, produces and delivers products and services to the market in accordance with the company's strategies and plans. We have in Figure 1b indicated that, when implementing the "4P" excellence model like 
any other excellence model, there is a need for management tools and techniques (here exemplified with Lean) as well as the right organizational culture (here exemplified with customer orientation and innovativeness).

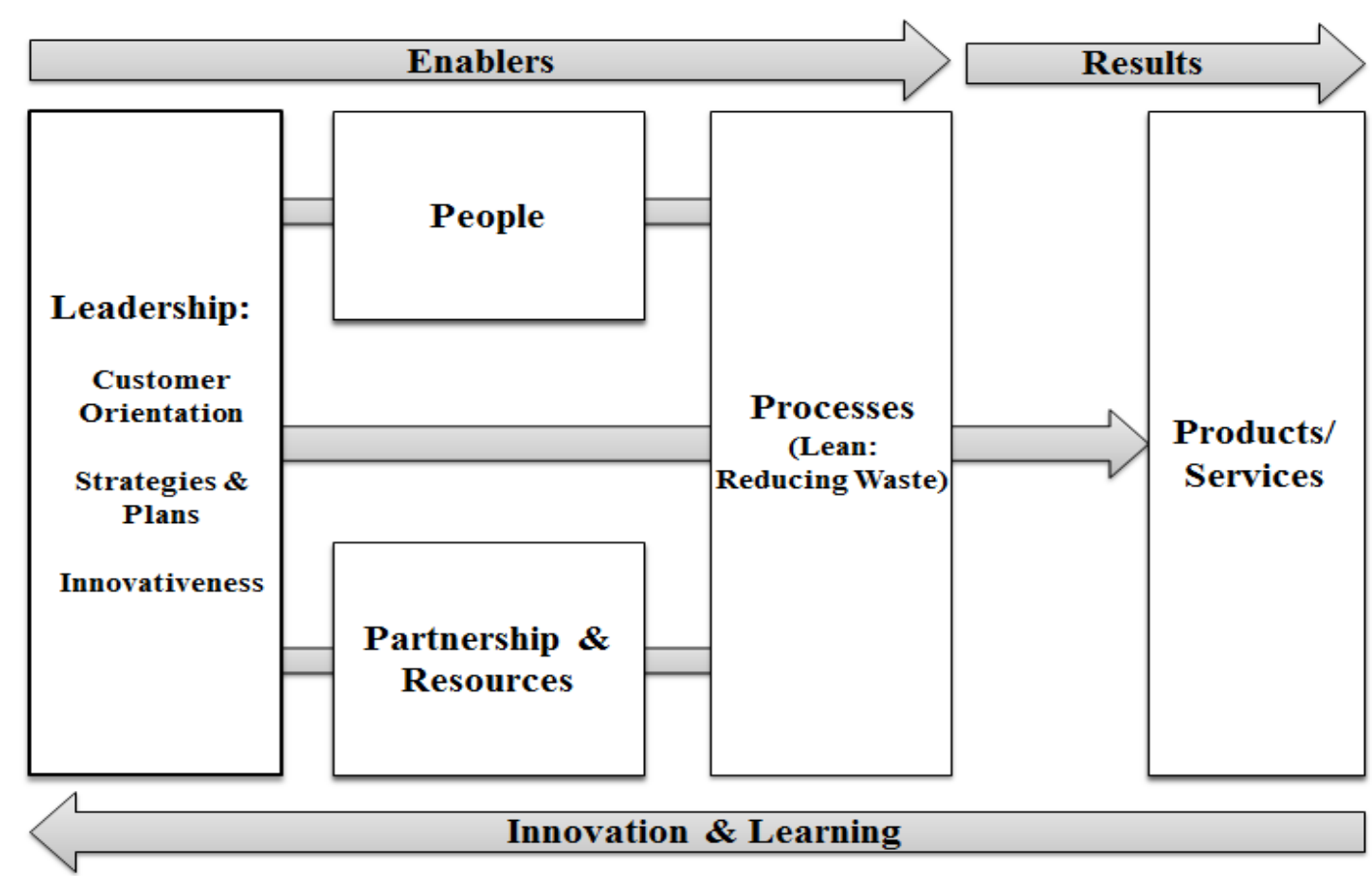

Figure 1b. The “4P” Excellence Model

What kind of management tools and techniques are needed depends on the context which also is the case in relation to organizational culture. So the BEM in Figure 1b should only be regarded as an example of an excellence model which may fit to a specific company's context at a specific time.

Figure 1b was in fact first developed for a Danish manufacturing company's context when the aim was to assess the company's technology center, meaning the processes of innovation and new product development (Dahlgaard-Park \& Dahlgaard, 2008, p.77-94). Parallel with that it was adapted to other organizations such as Post Denmark (Dahlgaard \& Dahlgaard-Park, 2004) and a Danish hospital clinic (Dahlgaard et al., 2011). The Danish hospital case shows 50 potential key performance indicators (= potential areas to address) to be considered when hospitals try to adapt the “4P” excellence model.

Business excellence models should always be flexible so that companies can adapt such models to new needs and challenges. The flexibility of the "4P" Excellence Model has been tested several times during the last 12 years when master students at Linköping University, Sweden, wrote their projects or master thesis in a 
company setting. Examples showing the model's flexibility vary from assessment of the whole company, a department, a key manufacturing process to the implementation of " $5 S$ " in a printing company. In all these applications the challenge for the students together with the company was to adapt the "4P" model to the actual context so that relevant results and key performance indicators could be included in the model and later measured by using traditional measurements combined with employees' perceived measurement scores collected by using the questionnaire approach referred to in section 2 (both importance and performance are assessed). An example of such measurement scores will be presented in the following section.

\section{An Overall Business Excellence Framework}

As a further response to the limitations of the existing BEMs discussed in section 2 we propose in this section a new overall business excellence framework (BEF). The proposed BEF (Figure 2) has a three-dimensional design which complements existing BEM helping to integrate appropriate management tools/techniques and the right organizational culture/characteristics.

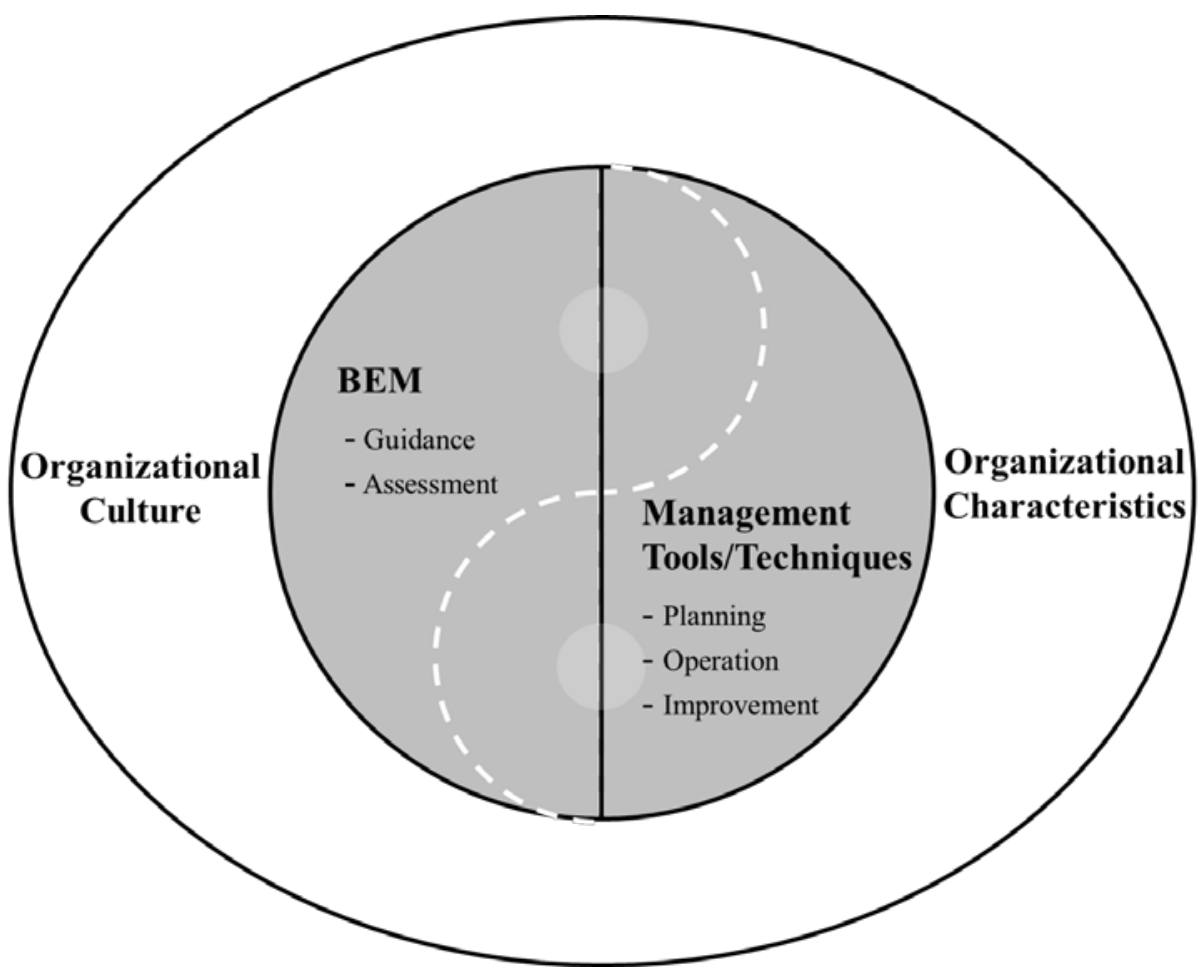

Figure 2. An Overall Business Excellence Framework

The applied BEM and Management Tools/Techniques are placed in the left and the right halves of the inner circle, respectively, indicating on the one hand that they serve as two independent functions in management control applications, and on the 
other hand, that the two functions should be integrated as one entity in a circle. The dotted line in the circle means that the two functions are not only coming together to become one but also a step further to become interdependent of each other as 'Yin and Yang' in Chinese Taoism. This metaphor indicates also that BEM should be institutionalized into an organization to provide the overall guidance for pursuing business excellence (BE), and the management tools/techniques should complementary support the activities in the ongoing pursuit of BE.

The third dimension placed in the outer circle indicates that in order to be successful in the journey towards BE a 'desirable organizational culture' should be cultivated. It is important here to emphasize that the 'desirable organizational culture' has to be identified and defined not only by the top management team but by all members in the organization (Dahlgaard \& Dahlgaard-Park, 1999, 2004) and should be communicated, deployed, practiced, checked/measured and reflected like any other strategic process initiated by top management.

Post Denmark had success in building a total quality culture called TIQ (= Total Involvement in Quality) focusing on the five TQM principles/characteristics: Leadership, Customer Focus, Continuous Improvements, Everybody's Participation, and Focus on Facts (Dahlgaard \& Dahlgaard-Park, 2004). Toyota needed only the following two principles called the DNA of the Toyota Production System: Respect for People, and Continuous Improvements (Dahlgaard \& Dahlgaard-Park, 2006). Samsung has built their corporate culture around the core values of people, excellence, change, integrity and co-prosperity.

These three examples illustrate that building the needed organizational culture varies from company to company because it is context dependent like the other two dimensions of the overall BEF.

Each of the three dimensions in the overall BEF will be discussed in more detail in the following.

\section{Business Excellence Models}

As indicated above the use of BEM has two purposes: One is guiding the organization towards BE, and the other is conducting assessment of the performance. Guiding towards BE is the primary purpose, and conducting assessment is the secondary purpose.

The MBNQA, the EFQM Excellence Model and the Deming Prize are the three most well-known BEMs. Adopters may choose one of them in terms of their preferences or purpose but other excellence models may also be used such as the "4P" excellence model. If a company has an ambition to apply for a quality award some time in the future then it makes sense to use the award model also for management control purposes eventually in a simplified version. Grundfoss used the EFQM 
Excellence model in the period 1995-1999 both as a management control model and an assessment model before they applied for the Danish Quality Award in 1999. The experiences expressed in their self-assessment document were (not externally available):

Since 1995 managers and employees have been working in line with the EFQM Excellence model. The model has provided managers and employees with a common frame of reference - a common language. It supports the organisation's learning processes and readiness to change.

Regarding the use of alternative BEMs, Abdullah et al. (2012) suggested a new comprehensive 'value-based total performance excellence model' containing 11 excellence criterions and 6 values under each criterion. The motive of the suggested model was that 'intangible measurements were not directly addressed in other excellence models'. Campatelli et al. (2011) suggested a simplified approach based on a simplified version of the EFQM model and Six Sigma for the implementation of TQM principles in a university administration. Asif et al. (2011) suggested that the existing BEMs should be revised to more comprehensively address the issue of sustainability; Mohammad et al. (2011) developed a new BEM to be used as an overarching framework for managing and/or aligning multiple improvement initiatives within the organization, and $\mathrm{Lu}$ et al. (2011) suggested a simplified framework in four dimensions which, according to the authors, better than existing excellence models supports the measurement, management and delivery of competitive performance at a 'world-class' level. Lu et al., as well as many others, stress the importance of firm-specific and situation-sensitive means of evaluations.

The "4P" excellence model has been accepted as an alternative and attractive BEM for many SME companies because of the model's simplicity having only five criterions (Leadership, People, Partnerships, Processes, and Products/Services) each of which having a set of potential key performance indicators (KPIs). The 50 potential KPIs suggested for healthcare applications contain a mixture of performance indicators related to Core Values, Core Competencies as well as Performance Results (Dahlgaard et al., 2011). The organisation chooses the KPIs which best fit to the context, maturity and the purpose because each organization is unique and should be treated so. Some KPIs are common for most companies while others should be specific for the context, maturity and purpose. Healthcare (Dahlgaard et al., 2011) is different from Post Offices (Dahlgaard \& Dahlgaard-Park, 2004) which again are different from manufacturing companies' contexts (Dahlgaard-Park \& Dahlgaard, 2008, 2010).

Assessment is the secondary purpose of using a BEM. For this purpose, the eight-step process proposed by Porter \& Tanner (2004, p. 287-312), and the quality 
award procedures proposed by award-in-charge organizations are good examples for reference purposes in relation to award applications. Seen from a company's viewpoint self-assessment is used to diagnose strengths/weaknesses of the organization.

In any application of BEM a BE criteria system and its measurement scale have to be chosen at the start (see Dahlgaard-Park \& Dahlgaard, 2010, and Dahlgaard et al., 2011). In this process it is important not to use uncritically the existing BEM's criterion weights because those weights may only make sense in relation to an award application. In the journey towards excellence the weights of each criterion and sub-criterion varies from company to company and from year to year depending on the context.

\section{Management tools/techniques}

In light of the above discussion the use of BEM for conducting assessment serves basically as the function of 'check' in Deming's PDCA management cycle. To fulfill the whole PDCA cycle organizations need to incorporate other management tools or techniques for the functions of 'plan', 'do' and 'action'.

In the second major dimension of the suggested overall BEF we categorize the management tools/techniques as 'planning', 'operation' and 'improvement' tools/ techniques which respectively represent the three management functions, 'plan', 'do' and 'action'.

For example SWOT, Ho-Shin Planning (Policy Deployment/Strategic Management), Balanced Score Card (BSC), Segmentation Targeting Positioning (STP), etc. are some of the most popular management tools/techniques for the 'planning' of an organization;

5S, Supply Chain Management (SCM), Enterprise Resource Planning (ERP), Just-in-Time (JIT)/ Toyota Production System (TPS), Project Management (PM), Total Preventive Maintenance (TPM), Knowledge Management (KM) , etc. are some of the most popular tools for the 'operation' of an organization;

Quality Control Circles (QCC), Six Sigma (6б), Business Process Reengineering (BPR), Benchmarking Management (BM), Change Management (CM), etc. are some of the most popular tools for the 'improvement' of an organization.

As the use of BEM has several purposes the same is the case with management tools/ techniques. The simultaneous and overlapping use of management tools/techniques fosters not only organizational improvements but they are also a pre-condition for effective and efficient organizational planning and operations, which again are a pre-condition for organizational improvements as indicated in the PDCA cycle. 


\section{Organizational culture/characteristics}

Cultivating the right organizational culture is the third major dimension of the suggested overall BEF. It is placed in the outer circle, surrounding the other two dimensions, implying that it is impossible to attain $\mathrm{BE}$ without the right organizational culture. Two issues arise in this respect; one is what constitutes the right organizational culture/characteristics, and the other is how it can be cultivated and maintained.

In response to the first issue, we will emphasize that the right or desired organizational culture may be different from organization to organization. As we have seen from Samsung, Toyota, Post Denmark etc. priority has been given to different core values in the different organizations. Besides, several empirical studies have investigated and identified the value characteristics which were important for changing specific organizations from mediocre to excellent (see for example Peters \& Waterman, 1982 and Collins, 2001). Such value characteristics should not be copied but should instead be an inspiration for companies and managers when deciding on the desired company culture before embarking on the journey towards BE.

In response to the second issue, how the organizational culture/characteristics can be cultivated in an organization, we have observed that there are many ways to do that. Samsung studied Toyota but chose its own way. Post Denmark did the same inspired by what they have learned from theory (education), their own and other companies' good as well as bad experiences. A strong input was also a questionnaire self-assessment based on 558 managers' perception of simple statements related to the EFQM Excellence Model's 9 criterions (Dahlgaard \& Dahlgaard-Park, 2004). This questionnaire self-assessment was in fact a simple way to measure the existing quality culture in Post Denmark and it was easy to identify what kind of culture should be changed first. For example one of the big gaps under the leadership criterion was related to the statement:

"Leaders always show recognition when people have done a good job".

On a scale from 1 to 7 the average importance score of the 558 managers was about 6.10 while the average agreement (=performance) on the same scale was about 3.6. By discussing this result it was obvious for managers as well as ordinary employees that Post Denmark had a bad culture related to recognition, and everybody understood that such a bad culture had to be changed so that recognition became "a way of life" for all managers. The next step was then to discuss how to change the culture related to recognition as well as other cultural weak areas identified through the questionnaire self-assessment.

A suggested 4-step procedure for changing a company's culture includes (Dahlgaard et al., 1998; Dahlgaard-Park et al., 1998; Dahlgaard et al., 1998; 2002, pp. 
261-289):

1. Setting goals and strategies for building up a new culture (Plan),

2. Education, training \& communication (Do),

3. Identify gaps based on feedback from training and everyday practice (Study),

4. Establish/implement activities for closing the gaps (Action).

\section{Implications of the suggested BEF}

Having developed the overall BEF the implications of the suggested framework are now considered further. The trinity concept is used to depict the three dimensions of the overall BEF as a whole, and Figures 3 and 4 present the illustrations of the trinity of the framework.

The word 'trinity' is derived from Latin 'trinitas' which means 'the number three, a triad'. The corresponding word in Greek means 'a set of three'. In this paper, the correspondence with the trinity through its etymology from Latin and Greek refers to the three dimensions of the proposed framework which are united as one goal leading towards excellence. This indicates that the fusion of BEM and management tools/techniques is a 'must' when implementing BEM, which further has to be fused together with cultivating the right organizational culture/characteristics (Figure 3). Here we argue that cultivating the right organizational culture is normally the most important for companies embarking on the journey towards BE. The reason is that we often find the biggest gaps here because the culture dimension has often been ignored in the past (Dahlgaard \& Dahlgaard-Park, 2006).

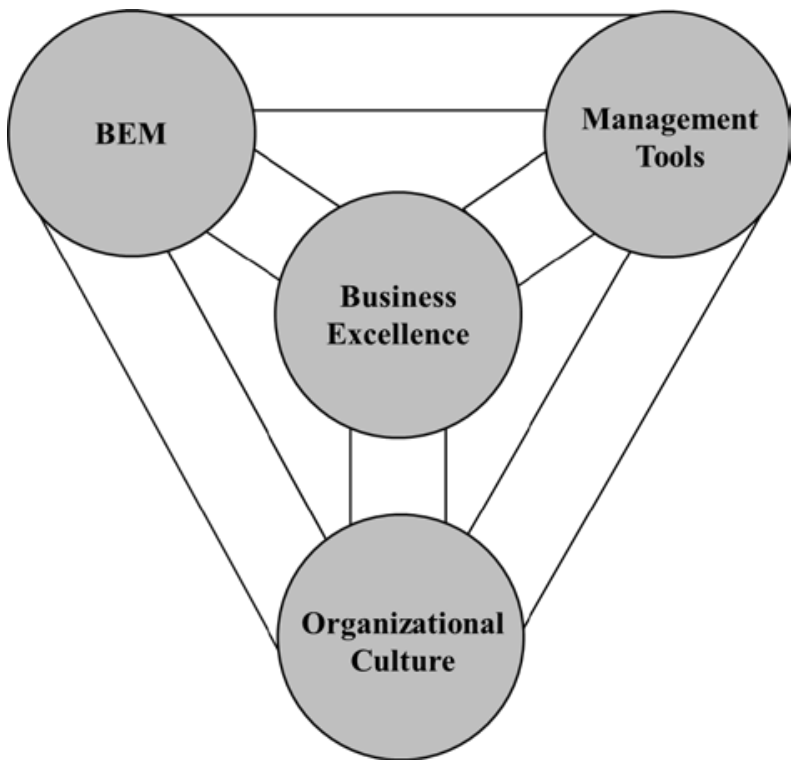

Figure 3. The trinity of the proposed BEF (Illustration I)

Figure 4 presents another illustration in terms of three figurations of a person. The BEM is compared to the bones/ skeleton of a human being, the management 
tools/ techniques represent flesh and blood, and the organizational culture/ characteristics represent the mind/ spirit. This metaphor indicates that 'excellence' can only be achieved under the situation of the three figurations having worked together harmoniously as a whole. The idea of this implication is inspired by the trinity of human needs proposed by Dahlgaard-Park (2012). The author postulated that balancing the three types of human needs, physical/biological needs, mental needs and spiritual needs (core values) is a precondition for heading a human being to happiness and prosperity.

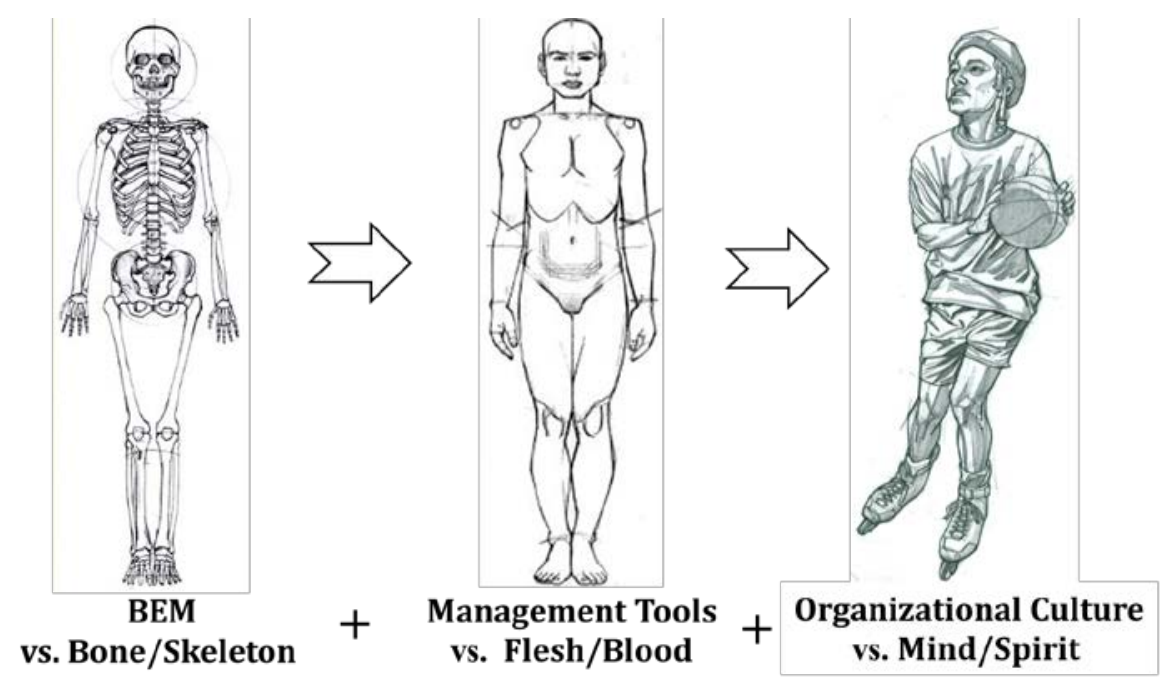

Figure 4. The trinity of the proposed BEF (Illustration II)

\section{Case: Boeing Aerospace Support (BAS)}

Boeing is one of the three organizations so far that has won the MBNQA twice (1998 and 2003). The first MBNQA was given to Boeing Airlift and Tanker Program. This organization won the manufacture category of the award. The other is Boeing AS which won the award in 2003 in the service business category.

In order to become an award winner, Boeing AS has put significant efforts to improve its performances. All key stakeholders of Boeing AS played important roles in the improvements so that the company could achieve a world class excellence level. Examples of Boeing AS's efforts for winning MBNQA are improvements of employee skills, optimistic strategies and good relationships between Boeing AS and their customers as well as suppliers.

Inspired by the criteria of MBNQA, Boeing created its own process management approach that stems from the MBNQA criteria. In addition to the process management approach, Boeing also created the managerial infrastructure that enables the assessment tools and improvement activities across different departments in the 
overall organization.

\section{Empirical Analysis}

The analysis of this case has been sub-divided into two phases. The aim of the first phase was to identify the elements used by Boeing in each of the three dimensions of the suggested overall BEF. The aim of the second phase was to collect evidences on how Boeing implicitly have responded to the three arguments (potential limitations) discussed in section 2. The analyzing data are secondary data acquired from the application summary of MBNQA and the operations of the company.

\section{The first phase}

Figure 5 shows the list of elements that were identified in each dimension of the overall BEF. For the BEM, the seven criteria of MBNQA are enlisted as the company uses MBNQA in their operations.

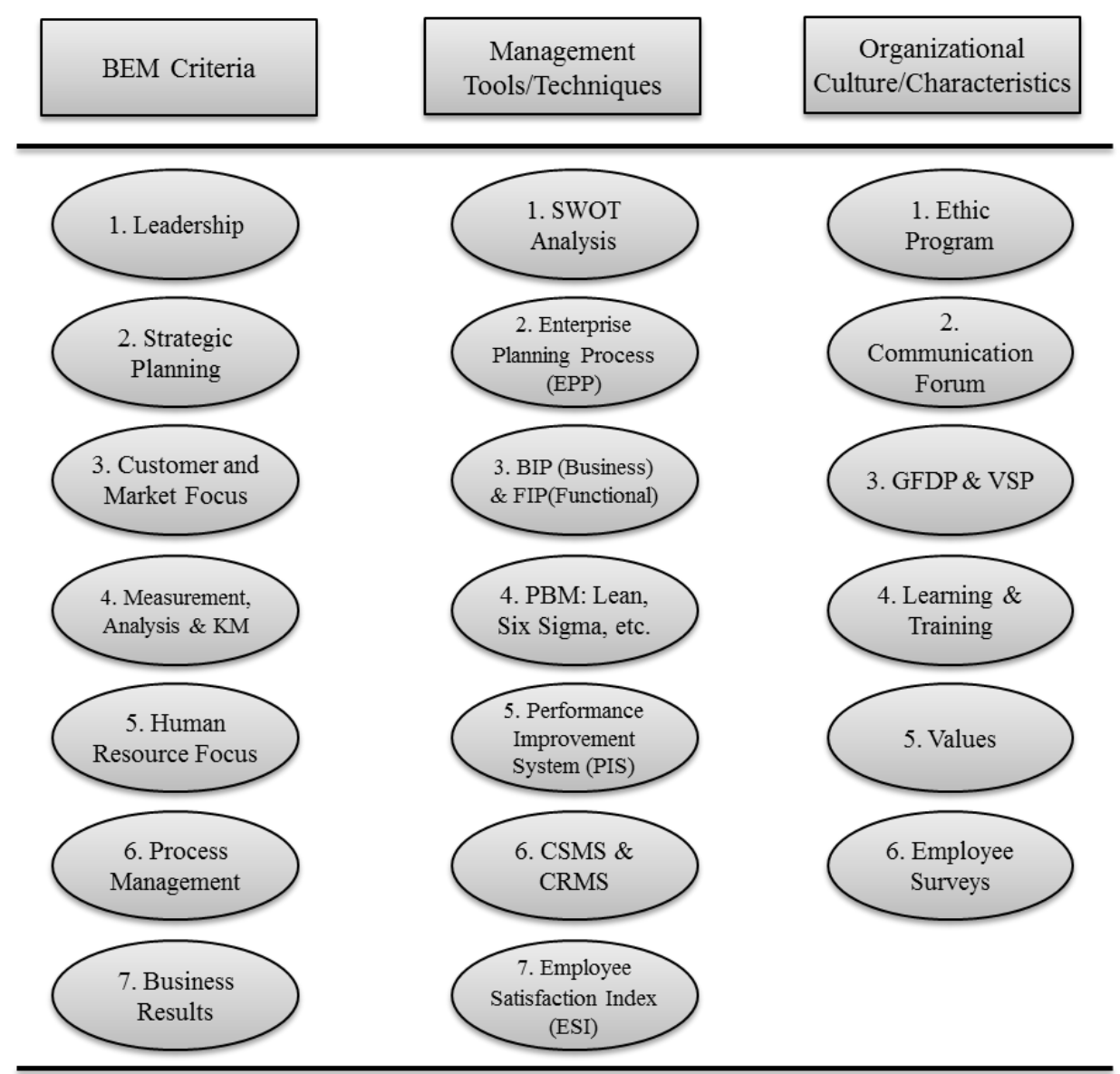

Figure 5. Elements of each Dimension of the Overall BEF

For the management tools and techniques, seven specific tools and techniques were identified to be used by Boeing.

The company performs 'SWOT Analysis' and develops the strategies to close 
identified gaps and achieve the strategic objectives.

'Enterprise Planning Process' (EPP) was another main tools used by Boeing, and as a part of the EPP, all Boeing AS businesses and major functions develop implementation plans for both the short- and the long-term time horizon.

Through the development and execution of 'Business Implementation Plans' (BIPs) and 'Functional Implementation Plans' (FIPs), the company converts its strategies into measurable actions. BIPs and FIPs are living documents that are reviewed and updated quarterly in the 'Business Performance Reviews'.

'Process Based Management' (PBM), which standardizes process management with a focus on customers and suppliers, uses different techniques and tools (Lean, Six sigma, etc.) to improve the operational processes.

In 'Performance Improvement System' (PIS), the strengths and opportunities for improvement identified from the feedback reports are analyzed, and improvement plans implemented to ensure continuous improvement throughout the company.

A web-based 'Customer Satisfaction Management System' (CSMS) has been designed with three main components: 'Top Issues' database, 'Customer Contact persons' (CCP) database, and 'Customer Relationship Management System' (CRMS). CRMS is an improvement to the organization's listening and learning processes. The customer focus process uses CSMS as the support system to ensure effective and prompt resolution of customer complaints. With CSMS, complaints are entered and tracked in the top issues database.

'Employee Satisfaction Index' (ESI) is the primary tool for the employee support and satisfaction, complemented by leadership assessment tools. The leadership team uses multiple tools to identify factors that drive employee well-being, satisfaction and motivation. The tools enlisted are used in the whole organization and are fundamental in the operation of Boeing. The employee survey includes twelve key questions to be included in the Employee Satisfaction Index (ESI). Factors represented by the twelve items have been shown empirically to correlate positively with work environment, improved productivity, motivation, turnover, unionization, customer satisfaction and business success.

For the mechanisms (programs) to cultivate organizational culture and characteristics toward excellence the following programs were identified.

'Boeing Ethics Program' is industry-recognized and communicates the organization's values and standards of ethical conduct to the workforce. 'Values' are clearly defined with the aim to be transmitted to all employees and hence to affect the culture and characteristics of the company. The Boeing values are 'Leadership', 'Integrity’, ‘Customer Satisfaction’, 'Quality’, ‘People Working Together', 'Diverse 
\& Involved team', ‘Good Corporate Citizenship’ and 'Enhancing Shareholder Value'. The leaders play an important role to reinforce the values of the company. The values are communicated to all employees through the ethics training program.

There are various 'Communication Forums' where the senior leaders formally review the business, site and functional performance. 'Goal Flow Down Process' (GFDP) is a system for selecting, aligning and integrating the performance goals and measures. 'Vision Support Process' (VSP) is a system for collecting, monitoring and reporting progress towards these goals.

Boeing invests heavily to create an environment for organizational and employee 'Learning and Training'. The employees have access to the Boeing Leadership Center where leadership courses and training are held on an ongoing basis. Ethics training is part of new employee orientation and mandatory annual ethics refresher training for all employees.

The company evaluates the effectiveness of the reward and recognition programs through 'Boeing Employee Survey' and by tracking progress towards recognition goals. These mechanisms are used to train and integrate all employees in the business excellence efforts and the effective deployment of the different tools and techniques.

\section{The second phase}

The aim of analyses in the second phase was to show how Boeing AS has responded to the three arguments (potential limitations) raised in section 2.

Argument 1: The existing BEM are essentially assessment tools instead of serving as general management tools.

The self-assessment and award review process serves in Boeing as the function of 'check' in the PDCA Leadership Cycle, missing the other three steps of the PDCA cycle. Figure 6 demonstrates how specific management tools and techniques are used to complete the whole PDCA Leadership Cycle.

The company performed self-assessments against the MBNQA criteria in 2000, 2001 and 2002. These assessments have driven significant improvements by highlighting strengths and opportunities for improvement and by creating a common framework for improvement at various sites.

As shown in Figure 6, the tools and techniques used are interrelated with the BEM criteria. The Baldridge model works in this way as a general management tool complementing the functions of the different tools and techniques. 


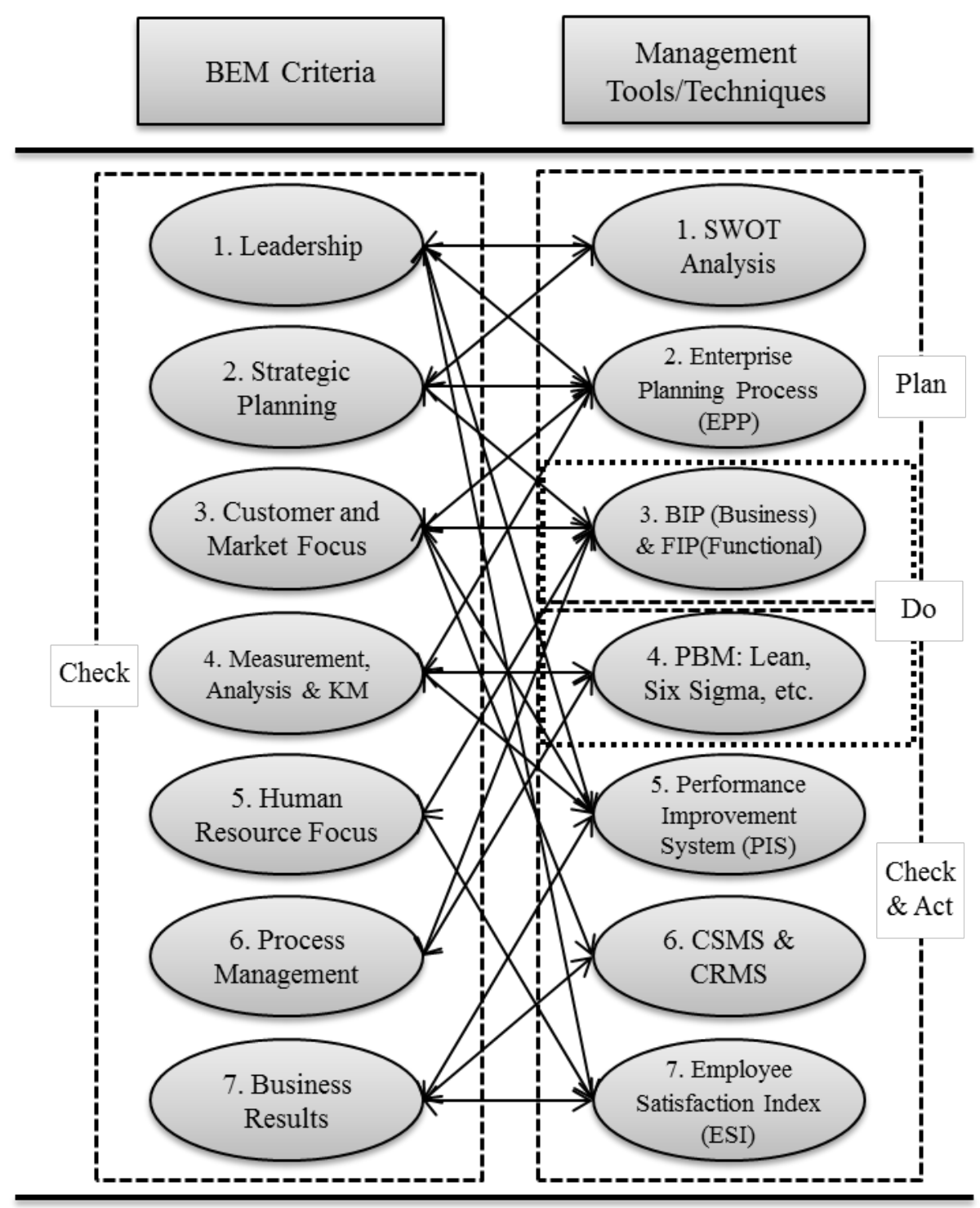

Figure 6. Analysis of Argument 1: Complementing the PDCA cycle

Argument 2: The existing BEMs are not sufficiently persuasive to yield 'Total Employee Involvement'.

Figure 7 shows the different groups of participants involved not only with each management tool and technique but also with the related BEM. For each group of participants, there is a description of the roles and the relationship with each criterion and each management tool, indicating a total employee involvement.

Stakeholder groups are formed for the customers, workforce, suppliers, community and shareholders. Through EPP the company ensures that all stakeholders are considered.

The top leader, David Spong, and his Leadership Team (LT) were responsible for implementing the leadership system, setting the strategic direction and to lead Boeing AS in the pursuit of the organizational vision, mission, and goals. The Strategic 
Business Council (SBC), a subset of the LT, executes EPP as well.

The Information Technology (IT) group uses tools/techniques to maintain reliable and secure hardware and software and to deliver user-friendly systems to the employees and the end users.

Through the process management methodology Process Owners select and analyse comparative data and information to determine areas for process improvement.

The company manages organizational knowledge in a variety of ways to provide employees the ability to apply, acquire and update market knowledge assets to serve customers and business partners.

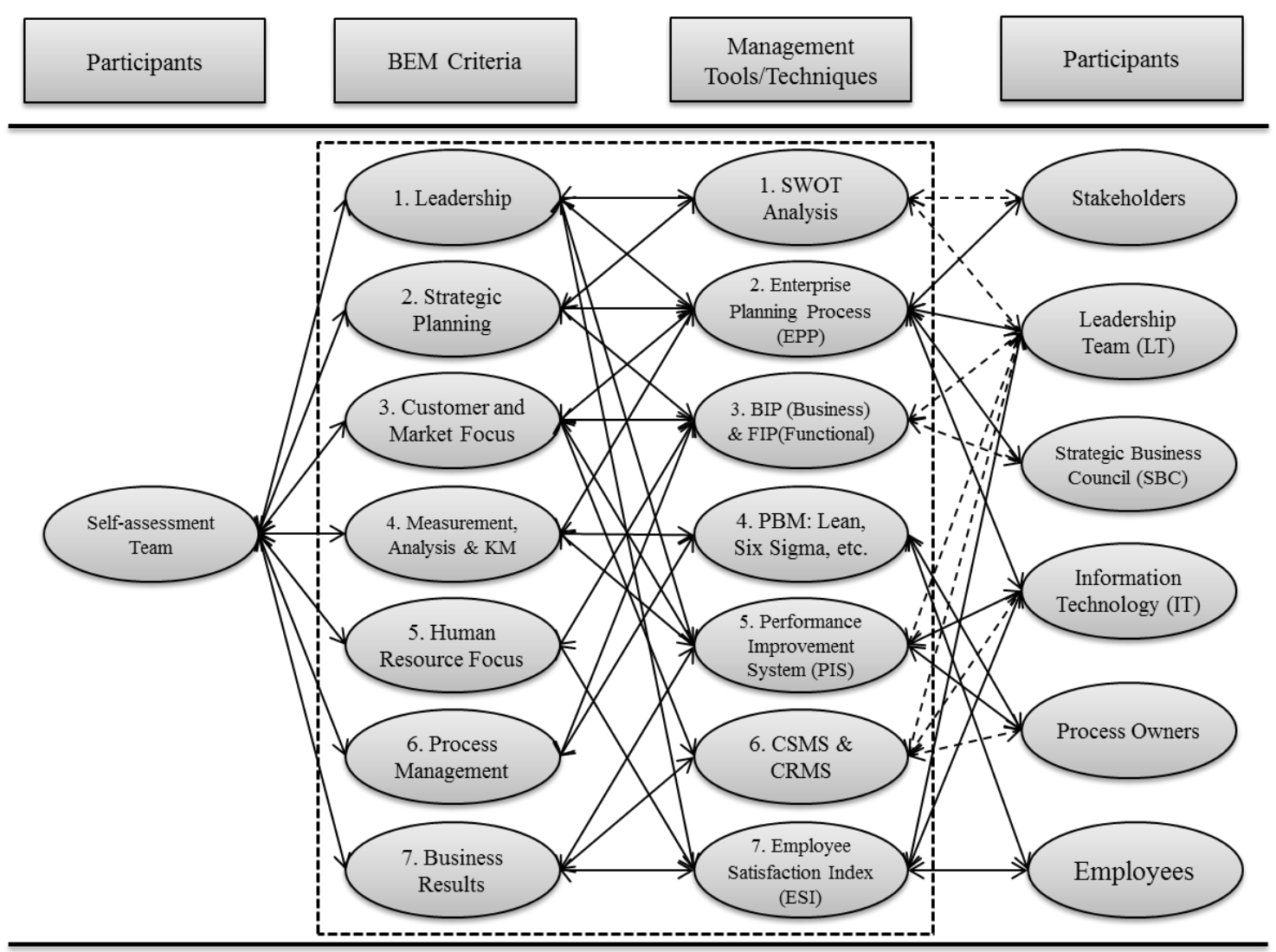

Figure 7. Analyses of Argument 2: Total Employee Involvement

Argument 3: The existing BEMs lack guidance for integration at the operational/ process level.

Figure 8 illustrates the mechanisms used by Boeing to involve all operational employees with a specific management tool or technique directly related with the BEM. For each mechanism, there is a description of relationships with each management tool and technique in order to illustrate how the integration at the operational level is achieved. Slashed lines are used if no data could support the specific management tool or technique is being promoted by the mechanism,.

In summary, the employees are dedicated in activities related to specific techniques and tools, which are integrated into BEM. 


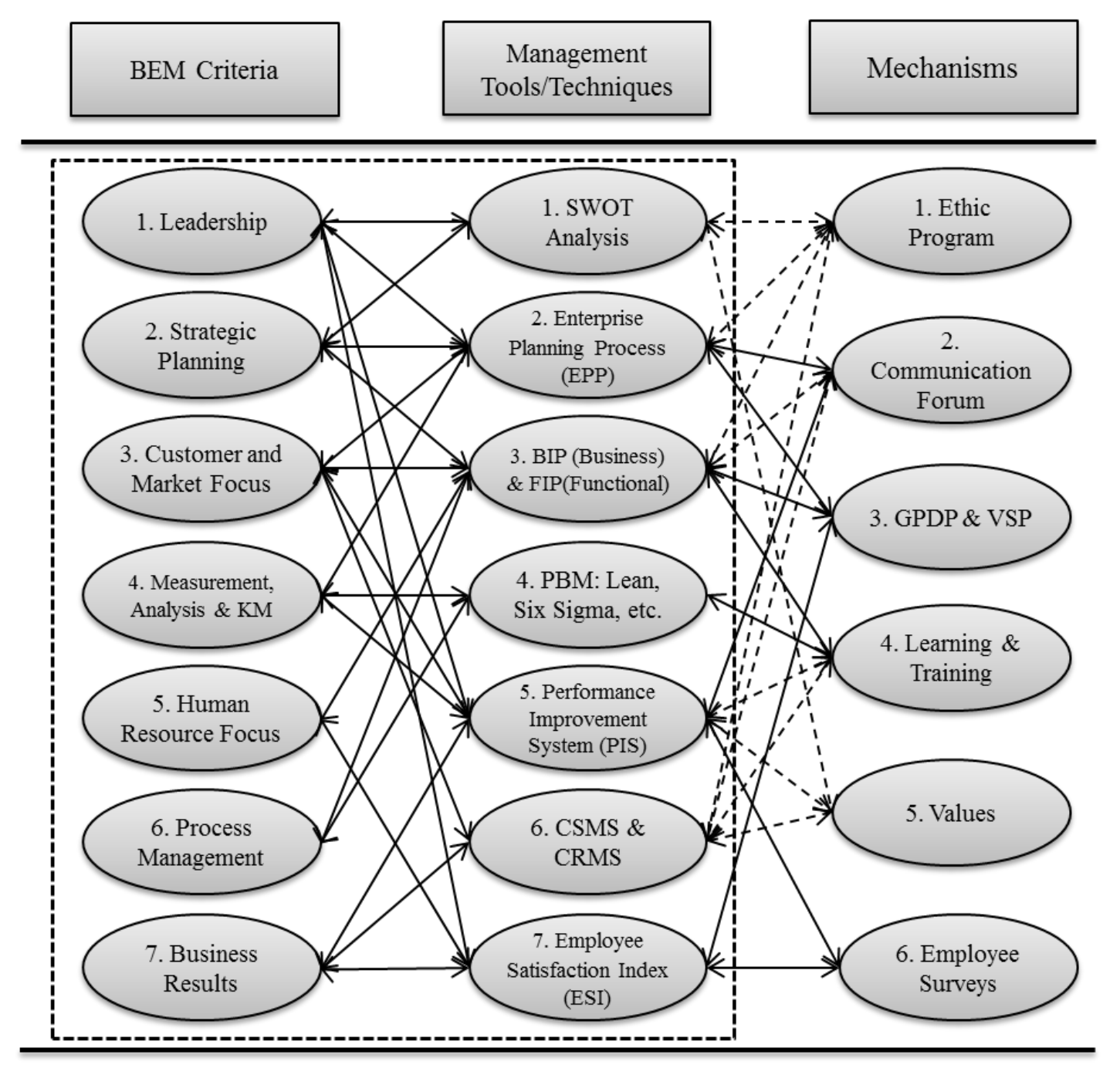

Figure 8. Analyses of Argument 3: Integration in the Operational Level

\section{Conclusions and Reflections}

By analyzing the Boing case it has been demonstrated that the analyzed world class company not only uses a BEM (the MBNQA) to guide the operations of the company but also uses a variety of management tools and techniques in its operation. Besides the BEM and the management tools and techniques, it has been demonstrated that the company uses specific mechanisms/ programs to cultivate its organizational culture and characteristics towards excellence. The case study has illustrated that all the three dimensions of the proposed overall BEF have been used in order to have a successful implementation of BEM having all employees actively involved.

However, it is important to understand that the overall BEF is a very flexible model for adaptation except that all the three dimensions of the model as well as their interrelationships should be understood, respected and practiced. The result of, for 
example, ignoring the culture dimension will, without doubt, lead to a lack of spirit (see Figure 4) at shop floor levels as well as at the middle management level. The result will with a high probability lead to failure if the company decides to implement TQM and BEM.

Boeing AS has shown how it was possible to build a desired organizational culture, and they understood that the chosen BEM has to be complemented with management tools/techniques as well as elements for building a new organizational culture.

It is interesting that the case analysis coincides the finding of a review of the recent 25 years quality research publications (Dahlgaard-Park et al., 2013). The finding revealed that the quality movement is now shifting from an initial focus on TQM and BE to the management tools, techniques and core values needed for building a quality and business excellence culture.

The Boeing AS case has also demonstrated how the overall BEF may serve as a flexible guiding framework to achieve excellence. The main message with the proposed overall BEF is that organizations need to work with all three parts: 1) the chosen BEM, 2) suitable tools \& techniques, and 3) suitable core values for building a desirable organizational culture. The proposed BEF complements existing BEMs by guiding companies in the adaptation and use of such models. We may then call the suggested overall BEF as a POKA YOKE (failure safe) tool for implementing business excellence models.

\section{References}

Abdullah, M., Hamid, M.R.A., Mustafa, Z., Husain, N., Idris, F. Suradi, N.R.M. \& Ismail, W.R. (2012). Value-based total performance excellence model: A conceptual framework for organisations. Total Quality Management \& Business Excellence, 23(5\&6), 557-572.

Asif, M., Searcy, C., Garvare, R. \& Ahmad, N. (2011). Including sustainability in business excellence models. Total Quality Management \& Business Excellence, 22(7), 773-786.

Boulter, L., Bendell, T. \& Dahlgaard, J.J. (2013). Total quality beyond North America: A comparative analysis of the performance of European Excellence Award winners. International Journal of Operations and Production Management, 33(2).

Campatelli, G., Citti, P. \& Meneghin, A. (2011). Development of a simplified approach based on EFQM Model and Six Sigma for the implementation of TQM principles in a university administration. Total Quality Management \& Business Excellence, 22(7), 691-704.

Chapman, C. (2000). The public and private faces of excellence. Quality World, 26(5), 30-32. 
Collins, J. (2001). Good to great: Why some companies make the leap...and others don't. New York: Harper Business Publications.

Corbett, L.M. \& Angell, L.C. (2011). Business excellence in New Zealand: Continuous improvement, learning, and change. Total Quality Management \& Business Excellence, 22 (7), 755-772.

Curkovic, S., Melnyk, S.A., Calantone R. \& Handfield, R.B. (2000). Validating the Malcolm Baldrige National Quality Framework through structural equation modeling. International Journal of Production Research, 38(4), 765-791.

Dahlgaard, J.J., Kristensen, K. \& Kanji, G. (1998; 002). Fundamentals of Total Quality Management. London: Chapman \& Hall; Cheltenham, UK: Nelson Thornes LTD, UK.

Dahlgaard, J.J., Dahlgaard-Park, S.M. \& Edgeman, R.L. (1998). Core value deployment: The need for a new renaissance. Total Quality Management \& Business Excellence, 9(4\&5), 45-50.

Dahlgaard-Park, S.M., Dahlgaard, J.J. \& Edgeman, R.L. (1998). Core values: The precondition for business excellence. Total Quality Management \& Business Excellence, 9(4\&5), 51-55.

Dahlgaard, J.J. \& Dahlgaard-Park, S.M. (1999). Integrating business excellence and innovation management: Developing a culture for innovation, creativity and learning. Total Quality Management \& Business Excellence, 10(4\&5), 465-472

Dahlgaard, J.J. \& Dahlgaard-Park, S.M. (2004). The 4P quality strategy for breakthrough and sustainable development. European Quality, 10(4), 6-19.

Dahlgaard, J.J. \& Dahlgaard-Park, S.M. (2006). Lean production, six sigma quality, TQM and company culture. TQM Magazine, 18(3), 216-237.

Dahlgaard-Park, S.M. (2008). Reviewing the European excellence model from a management control view. The TQM Journal, 20(2), 98-119.

Dahlgaard-Park, S.M. \& Dahlgaard, J.J. (2008). A strategy for building sustainable innovation excellence - A Danish study, in Klaus J. Zink (Ed.). Corporate Sustainability as a Challenge for Comprehensive Management, Physica-Verlag, Heidelberg, Germany: A Springer Company.

Dahlgaard-Park, S.M. \& Dahlgaard, J.J. (2010). Organizational learnability and innovability: A system for assessing, diagnosing and improving innovations. International Journal of Quality and Service Science, 2(2), 153-175.

Dahlgaard, J.J., Pettersen, J. \& Dahlgaard-Park, S.M. (2011). Quality and lean healthcare: A system for assessing and improving the health of healthcare organizations. Total Quality Management \& Business Excellence, 22(5), 671-689.

Dahlgaard-Park, S.M. (2012), Core values - the entrance to human satisfaction and commitment. Total Quality Management \& Business Excellence, 23(1), 125-140.

Dahlgaard-Park, S.M., Chen, C,K., Jang, J.Y. \& Dahlgaard, J.J. (2013). Diagnosing and prognosticating the quality movement - a review on the 25 years quality literature (1987-2011). Total Quality Management \& Business Excellence, 24(1).

Douglas, T.J. \& Judge, W.Q. (2001). Total quality management implementation and 
competitive advantage: The role of structural control and exploration. Academy of Management, 44(1), 158-169.

European Foundation for Quality Management (EFQM; 2010). EFQM Excellence Model 2010, Brussels, Belgium (www.efqm.org).

Evans, J. R. (2012). Beyond Performance Excellence: Research Insights from Baldrige Recipient Feedback. Total Quality Management \& Business Excellence, Vol. 23 (5), 489-506.

Fisher, C., Dauterive, J. \& Barfield, J. (2001). Economic impact of quality awards: Does offering an award bring returns to the state? Total Quality Management \& Business Excellence, 12(7), 981-987.

General Accounting Office (GAO) (1991). A Report on Management Practices: US Companies Improve Performance through Quality Efforts. Washington, DC: United States General Accounting Office.

Hansson, J. \& Eriksson, H. (2002). The impact of TQM on financial performance. Measuring Business Excellence, 6(4), 44-54.

Hausner, A. (1999). Business success and ABEF evaluation results: On the nexus between manufacturing results and frameworks for business excellence. Department of Mechanical Engineering, University of Wollongong.

Hendricks, K.B. \& Singhal, V.R. (1996). Quality awards and the market value of the firm: An empirical investigation. Management Science, 42(3), 415-436.

Hendricks, K.B. \& Singhal, V.R. (2000). The long-run stock price performance of firms with effective TQM programs as proxied by quality award winners. Management Science, 47(3), 359-368.

Heras-Saizarbitoria, I., Marimon, F. \& Casadesus, M. (2012). An empirical study of the relationships within the categories of the EFQM model. Total Quality Management \& Business Excellence, 23(5), 523-540.

Hoisington, S.H. \& Huang, T. (2000). IBM Rochester correlation on measurements of employee satisfaction, cost of quality, productivity, customer satisfaction, and market share. In: Naumann, E., Hoisington, S. (Eds), Customer Centered Six Sigma, ASQ Quality Press, Milwaukee, WI, 301-305.

Jackson, S. (2001). Successfully implementing total quality management tools within healthcare: What are the key actions? International Journal of Health Care Quality Assurance, 14(4), 157-163.

Jacob, R., Madu, C.N. \& Tang. C. (2004). An empirical assessment of the financial performance of Malcolm Baldrige Award winners. International Journal of Quality \& Reliability Management, 21(8), 897-914.

Jennings, P. \& Beaver, G. (1997). The performance and competitive advantage of small firms: A management perspective. International Small Business Journal, 15(2), 63-75.

Lee, S.M., Zuckweiler, K.M. \& Trimi, S. (2006). Modernization of the Malcolm Baldrige National Quality Award. International Journal of Production Research, 44(23), 5089-5106.

Liker, J.K. (2004). The Toyota Way-14 Management Principles from the World's 
Greatest Manufacturer. New York: McGraw-Hill.

Lu, D., Betts, A. \& Croom. S. (2011). Re-investigating business excellence: Values, measures and a framework. Total Quality Management \& Business Excellence, 22(12), 1263-1276.

Main, J. (1991). Is the Baldrige overblown? Fortune, 124(1), 62-65.

Mann, R. (2011). Awareness and impact of business excellence in Asia. Total Quality Management \& Business Excellence, 22 (12), 1237-1258.

McTeer, M.M. \& Dale, B.G. (1994). Are the ISO 9000 series of quality management system standards of value to small companies? European Journal of Purchasing \& Supply Management, 1(4), 227-235.

Melnyk, S.A. \& Denzler, D.R. (1996). Operations management: A value-driven approach. Chicago, IL: Irwin.

Miller, D. (1993). The architecture of simplicity. The Academy of Management Review, 18(1), 116-138.

Mohammad, M., Mann, R., Grigg, N. \& Wagner, J.P. (2011). Business Excellence Models: An overarching framework for managing and aligning multiple organisational improvement initiatives. Total Quality Management \& Business Excellence, 22(11),1213-1236.

Oakland, J.S. (1999). Total organizational excellence: Achieving world-class performance. Oxford and Boston: Butterworth-Heinemann.

Peters, T.J. \& Waterman, R.H. (1982). In search of excellence: Lessons from America's best-run companies. New York: Harper \& Row.

Powell, T.C. (1995). TQM as competitive advantage: A review and empirical study. Strategic Management Journal, 16(1), 15-37.

Porter, L.J. \& Tanner, S.J. (2004). Assessing business excellence: A guide to business excellence and self-assessment (2nd ed). Oxford: Butterworth-Heinemann.

Stephens, P.R., Evans, J.R. \& Matthews, C.H. (2005). Importance and implementation of Baldrige practices for small businesses. The Quality Management Journal, 12(3), 21-38.

Wilkes, N. \& Dale, B.G. (1998). Attitudes to self-assessment and quality awards: A study in small and medium-sized companies. Journal of Total Quality Management, 9(8), 731-739.

Wisner, J.D. \& Eakins, S.G. (1994). A performance assessment of the US Baldrige Quality Award winners. International Journal of Quality \& Reliability Management, 11(2), 8-25. 